\title{
Comparison in use of health services between a deprived and an endowed community
}

\author{
G N MARSH AND D M CHANNING \\ Norton Medical Centre, Norton, Stockton-on-Tees
}

SUMmaRY Two hundred and twenty eight deprived children were compared with a matched sample of more endowed children living in the same urban area. Both groups were served by the same experienced primary health care team. The deprived group had a significantly higher number of general practitioner consultations and admissions to hospital (aged under 5) and a significantly higher recorded prevalence of mental and psychological disturbance (aged 5-15). Accident and emergency attendances were significantly higher for the deprived group throughout childhood, as were non-attendances for medical care appointments. The deprived group had much worse rates of immunisation and significantly later immunisations; practical measures subsequently adopted to improve this uptake of immunisation are described.

Low social class has long been associated with comparatively poor health and low uptake of preventive care. The Black report attributed this to a self perpetuating cycle of socioeconomic deprivation, and the first objective of the report's recommendations was to give deprived children a better start in life. ${ }^{1}$

Our practice has consistently tried, in an unstructured way, to provide equal health care to patients of different social backgrounds. To assess our success, we have compared the recorded morbidity and state of immunisation of 228 matched pairs of deprived and more endowed patients under 16 years of age. The deprived group lived in the Blue Hall council estate, Stockton-on-Tees, a locality of severe socioeconomic deprivation. The more endowed controls, matched for sex and age, lived in a defined neighbouring area of pleasant private housing estates in north Norton, equidistant (one mile) from our practice premises. This work was part of a survey of patients of all ages from these two communities. $^{2}$

Our practice contains five full time and one part time experienced general practitioners, frequent trainees, and ancillary staff to the reimbursable maximum of two per doctor. It has three attached district nurses, usually two but sometimes three health visitors, and effective working liaison with a social worker, community psychiatric nurse, and marriage counsellor; in short, a comprehensive if slightly shoestring primary health care team to serve 15700 urban patients. It has excellent A4 medical records, ${ }^{3}$ supplemented by a microcomputer, a personal list policy, and no private patients and performs its own out of hours calls. Because of the close proximity of a large hospital, the practice is rarely involved in the initial treatment of accident and emergency cases.

\section{Method}

The sampling frame was the age-sex register of the practice on 30 September 1984 . The deprived group comprised all 228 patients from the Blue Hall council estate aged under 16 who had been registered with the practice for at least a year or born into the practice during that year. They comprised roughly $30 \%$ of the children on the estate. Each deprived patient was matched by sex and nearest birthdate with a control patient who satisfied the same conditions and lived in the defined endowed area. Close matching of birthdates was achieved.

All data were abstracted from each patient's comprehensive A4 medical record folder, ignoring entries after 30 September 1984. The number of entries on the included sheet 'summary of important illnesses and investigations' was noted, these having previously been entered by our trained staff using rigid guidelines. ${ }^{3}$ These entries were divided into physical and mental/psychological conditions. The numbers of consultant referrals and admissions to hospital were obtained from an analysis of the date ordered correspondence with hospital departments. Attendances at hospital accident and emergency 
departments were obtained from the 'casualty slips' returned by the hospital and invariably filed in the folders. Non-attendances at prearranged health care appointments of all types were abstracted for the last five years (since birth for children under 5). Because of the greater frequency of general practitioner consultations their numbers were abstracted for only three years, excluding telephone, nurse, and health visitor consultations.

The details and dates of immunisations were noted. 'Possible' and 'actual' scores were given: 4 for each triple immunisation plus polio ( 1 for each element), 4 for measles, and 3 for the diphtheria, tetanus, and polio booster. A child scored for receiving an immunisation at any age, excluding school leaving immunisations. In the absence of an immunisation it was necessary to postulate an age by which the child could reasonably be considered to have 'defaulted' on that immunisation: the 'deadline' ages used for this purpose were 6,9 , and 12 months for first, second, and third triple/polio and 2 and 5 years for measles and booster, respectively. Infection or contraindication before the deadline age reduced the possible score. Two examples may clarify this: a child of 10 months who had received only the first diphtheria, tetanus, and polio with pertussis immunisation medically contraindicated would have an actual score of 3 and a possible score of 6 ; a child aged 6 who had received only the first and second triple/polio immunisations and had contracted measles at 21 months (before the deadline age) would have an actual score of 8 and a possible score of 15 . Actual score as a percentage of possible was calculated for each child.

For this matched pair survey the statistical tests used were the Wilcoxon test for quantitative data and the McNemar test for categorical data. In one stated case where matched pairs were not being compared the $\chi^{2}$ test was used. All statistical significances were based on two tailed tests.

\section{Results}

Morbidity. (Table 1). There were no significant differences between the deprived children and

Table 2 Total occurrences of mental/psychological afflictions in deprived and control children grouped according to age

\begin{tabular}{|c|c|c|c|}
\hline & \multicolumn{3}{|l|}{ Age group (years) } \\
\hline & Under 5 (81 pairs) & \multicolumn{2}{|c|}{ 5-15 (147 pairs) } \\
\hline & Deprived Control & Deprived & Control \\
\hline Non-accidental injury & 1 & 9 & \\
\hline Socialemotional problem & 2 & 7 & \\
\hline Behavioural problem & 1 & 7 & 1 \\
\hline \multicolumn{3}{|l|}{ Educationally/mentally } & 1 \\
\hline Speech/language problem & 1 & 1 & 2 \\
\hline Hyperkinetic syndrome & & 1 & 1 \\
\hline \multicolumn{4}{|l|}{$\begin{array}{l}\text { Gilles de la Tourette's } \\
\text { syndrome }\end{array}$} \\
\hline Total & 5 & 29 & 6 \\
\hline
\end{tabular}

Table 1 Comparison of recorded morbidity in deprived and control children grouped according to age

\begin{tabular}{|c|c|c|c|c|c|c|c|}
\hline & \multirow{3}{*}{$\begin{array}{l}\text { Children } \\
\text { group }\end{array}$} & \multicolumn{6}{|c|}{ Age group (years) } \\
\hline & & \multicolumn{3}{|c|}{ Under 5 (81 pairs) } & \multicolumn{3}{|c|}{ 5-15 (147 pairs) } \\
\hline & & $\begin{array}{l}\text { No }(\%) \text { of } \\
\text { patients }\end{array}$ & $\begin{array}{l}\text { Total } \\
\text { occurrences }\end{array}$ & Significance & $\begin{array}{l}\text { No }(\%) \text { of } \\
\text { patients }\end{array}$ & $\begin{array}{l}\text { Total } \\
\text { occurrences }\end{array}$ & Significance \\
\hline $\begin{array}{l}\text { Serious illnesses: } \\
\text { Physical }\end{array}$ & $\begin{array}{l}\text { Deprived } \\
\text { Control }\end{array}$ & $\begin{array}{ll}22 & (27) \\
27 & (33)\end{array}$ & $\begin{array}{l}29 \\
29\end{array}$ & & $\begin{array}{ll}78 & (53) \\
72 & (49)\end{array}$ & $\begin{array}{l}137 \\
122\end{array}$ & \\
\hline Mental & $\begin{array}{l}\text { Deprived } \\
\text { Control }\end{array}$ & $\begin{array}{ll}5 & (6) \\
0 & (0)\end{array}$ & $\begin{array}{l}5 \\
0\end{array}$ & & $\begin{array}{r}25(17) \\
4 \quad(3)\end{array}$ & $\begin{array}{r}29 \\
6\end{array}$ & $* * *$ \\
\hline Consultant referrals & $\begin{array}{l}\text { Deprived } \\
\text { Control }\end{array}$ & $\begin{array}{l}19(23) \\
15(19)\end{array}$ & $\begin{array}{l}22 \\
20\end{array}$ & & $\begin{array}{l}44(30) \\
45(31)\end{array}$ & $\begin{array}{l}61 \\
74\end{array}$ & \\
\hline Hospital admissions & $\begin{array}{l}\text { Deprived } \\
\text { Control }\end{array}$ & $\begin{array}{l}27(33) \\
12(15)\end{array}$ & $\begin{array}{l}49 \\
15\end{array}$ & ** & $\begin{array}{ll}41 & (28) \\
34 & (23)\end{array}$ & $\begin{array}{l}59 \\
55\end{array}$ & \\
\hline Casualty attendances & $\begin{array}{l}\text { Deprived } \\
\text { Control }\end{array}$ & $\begin{array}{ll}36 & (44) \\
23 & (28)\end{array}$ & $\begin{array}{l}67 \\
29\end{array}$ & $* *$ & $\begin{array}{l}87(59) \\
72(49)\end{array}$ & $\begin{array}{l}232 \\
117\end{array}$ & $* * *$ \\
\hline
\end{tabular}

${ }^{*}$ At $5 \%$ level: $(0 \cdot 0)<\mathrm{p}<0 \cdot 05$

${ }^{* *}$ At $1 \%$ level: $0 \cdot(001<\mathrm{p}<0 \cdot(0)$

***At $0 \cdot 1 \%$ level: $\mathrm{p}<(0) \cdot(0) 1$.

All data abstracted over five years, except general practitioner consultations (three years). 
controls as far as recorded serious physical illnesses and consultant referrals were concerned.

Mental or psychological afflictions were much more prevalent among deprived children than controls, particularly in the 5-15 age group where the ratio was almost 5 to 1 . The most common items were non-accidental injuries, social/emotional problems associated with parental inadequacies, and behavioural problems (Table 2).

Admissions to hospital were three times as high for the deprived-children aged under 5 as for their controls, but there was no significant difference in the 5-15 age group. Casualty attendances by deprived children were about twice as high as controls in both age groups. Compared with the controls, general practitioner consultations for the deprived group were $50 \%$ higher for those under 5 but $20 \%$ lower for those 5-15.

Table 3 Comparison of immunisation state in deprived and control children grouped according to age. Values are No $(\%)$

\begin{tabular}{|c|c|c|c|c|}
\hline & \multicolumn{4}{|c|}{ Age group (years) } \\
\hline & \multicolumn{2}{|c|}{ Under 5 (69 pairs) } & \multicolumn{2}{|c|}{$5-1.5$ ( 8.5 pairs) } \\
\hline & Deprived & Control & Deprived & Comtrol \\
\hline No immunisation & $10(14)$ & () (0) & $11(1.3)$ & $0 \quad(0)$ \\
\hline \multicolumn{5}{|l|}{ Part immunisation $(\%)$ : } \\
\hline $1-24$ & $2 \quad(3)$ & () $(0)$ & $11(1.3)$ & 1 (1) \\
\hline $25-49$ & $8(12)$ & 1 (1) & $19(22)$ & $5 \quad(6)$ \\
\hline $50-74$ & $10(14)$ & 3 (4) & $17(20)$ & $13(15)$ \\
\hline $75-99$ & $9(13)$ & $7(10)$ & $14(16)$ & $35(41)$ \\
\hline Full immunisation for age & $30(43)$ & $58(84)$ & $1.3(1.5)$ & $31(36)$ \\
\hline p Value (at $1 \%$ level) & \multicolumn{2}{|c|}{$<(0 \cdot()(0) 1$} & \multicolumn{2}{|c|}{$<0) \cdot(0) 1$} \\
\hline
\end{tabular}

*Children under 6 months old were omitted.
Non-attendances. For prearranged health care appointments (therapeutic and preventive combined), 20 deprived and three control children under 5 had one or more non-attendances; for the 5-15 age group the corresponding figures were 36 deprived and 12 control children $(\mathrm{p}<0.001$ for both age groups).

Immunisations. Immunisation data for the 81 pairs aged under 5 seemed reliable, but the data for 62 of the 147 pairs aged 5-15 were marred by uncertainty or complete absence for one or both members who had arrived from other practices. Comparison of immunisations for this age group was therefore restricted to the remaining 85 pairs.

Deprived children had much worse immunisation scores than their controls in both age groups (Table 3 ). About $86 \%$ of deprived babies were presented for the first triple immunisation, but the proportion declined to about $60 \%$ by the third triple immunisation and less than $50 \%$ for the booster (Table 4). Five deprived children (but no controls) in each age group were restarted on a new course of triple immunisations after a lapse, but in only two of these 10 cases was the renewed course completed. Three deprived parents (but no controls) refused all immunisations for their children. Four other deprived parents (and two controls) refused measles immunisation. More deprived parents refused pertussis immunisation than control parents, although fewer parents in both groups did so in the last five years (Table 4).

Measles was the only immunisation for which previous infection and contraindication (at that time eczema) proved important. The breakdown (Table 5) again showed the poorer state of the deprived children. For both deprived and control children,

Table 4 Immunisations given to (or medically contraindicated in) deprived and control children grouped according to age. Values are No $(\%)$

\begin{tabular}{|c|c|c|c|c|c|c|c|}
\hline & \multicolumn{7}{|c|}{ Age group (years) } \\
\hline & \multicolumn{4}{|l|}{ Under 5} & \multicolumn{3}{|c|}{$5-1.5$ (8.5 pairs) } \\
\hline & (Pairs) $)_{+}^{+}$ & Deprived & Control & Significance & Deprived & Control & Significance \\
\hline First triple/polio & $(69)$ & $59(86)$ & $69(1(0))$ & $+\cdots$ & $73(86)$ & $84(99)$ & $* *$ \\
\hline Second triple/polio & $(67)$ & $52(78)$ & $66(99)$ & *t* & $62(7.3)$ & $83(98)$ & $* * *$ \\
\hline Third triple/polio & $(62)$ & $39(63)$ & $60(97)$ & 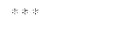 & $51(60)$ & $79(93)$ & $* * *$ \\
\hline Measles & $(51)$ & $34(67)$ & $44(86)$ & * & 31 & $57(67)$ & $*$ \\
\hline Booster & (15) & $7(47)$ & $13(87)$ & & $36(42)$ & $77(91)$ & $* * *$ \\
\hline $\begin{array}{l}\text { Pertussis omitted } \\
\text { (without contraindication) }\end{array}$ & & $20(29)$ & $\begin{array}{ll}6 & (9)\end{array}$ & $* *$ & $45(53)$ & $33(39)$ & $(\dagger)$ \\
\hline
\end{tabular}


Table 5 Measles immunisations in deprived and control children grouped according to age. Values are No (\%)

\begin{tabular}{|c|c|c|c|c|}
\hline & \multicolumn{4}{|c|}{ Age group (years) } \\
\hline & \multicolumn{2}{|c|}{ Under 5 (51 pairs) } & \multicolumn{2}{|c|}{ 5-15 (85 pairs) } \\
\hline & Deprived & Control & Deprived & Contro \\
\hline Immunisation given & $20(39)$ & $35(69)$ & $19(22)$ & $41(48)$ \\
\hline Medically contraindicated & $5(10)$ & 7 (14) & $6(7)$ & $10(12)$ \\
\hline Infection before 2 years & $9(18)$ & 2 (4) & 6 (7) & $6(7)$ \\
\hline Defaulted or refused & $17(33)$ & $7(14)$ & $54(64)$ & $28(33)$ \\
\hline p Value* & \multicolumn{2}{|c|}{$0 \cdot 001<\mathrm{p}<0.01 \dagger$} & \multicolumn{2}{|c|}{$<0 \cdot 001 \ddagger$} \\
\hline
\end{tabular}

${ }^{*} \chi^{2}$ test.

tAt $1 \%$ level.

$\ddagger$ At $0 \cdot 1 \%$ level.

however, those under 5 showed a distinct improvement compared with those 5-15.

The 1984 national rates of immunisation ${ }^{4}$ for diphtheria, tetanus, and polio were $84 \%,{ }^{4}$ which compared with $61 \%$ for our deprived children aged under 5 and $97 \%$ for their controls. Corresponding figures nationally, for our deprived children, and for our controls for pertussis were $52 \%, 44 \%$, and $87 \%$ and for measles were $56 \%, 39 \%$, and $69 \%$, respectively.

Median immunisation dates from birth were significantly later for deprived children. For those aged 5-15 this time lag in median dates varied from seven to 22 weeks for various immunisations. For those under 5, however, compared with those 5-15, not only did the median dates of the controls improve (except for measles) but also the time lag for the deprived children of two to four weeks for the various immunisations was considerably smaller.

\section{Discussion}

Our survey data together with 1981 census statistics ${ }^{4}$ give the following broad picture of the typical Blue Hall estate deprived child. There is roughly a $60 \%$ chance that his father is unemployed and over a $50 \%$ chance that the family is of social class IV or V. Likewise, there is a $50 \%$ chance of his having three or more siblings or alternatively a $10 \%$ chance that he belongs to a single parent family. There is over a $40 \%$ chance that his mother suffers from or has had at least one mental or psychological ailment and a probability that she is worse than her more endowed control on all other morbidity criteria. There is a $90 \%$ chance that one parent smokes and almost a $50 \%$ chance that both do. The family lives in crowded deprivation amid poor surroundings, has a poor diet, consumes a fair amount of alcohol, and almost certainly has no telephone or car. Within that setting it is not surprising that the children reflect the high morbidity, high rate of non-attendance, and low uptake of preventive care of their elders in this deprived community.

Deprived children under 5 had a significantly higher number of admissions to hospital and general practitioner consultations than their controls (their consultant referrals are understated because consultant attention in hospital was not included). These differences may be attributed partly to the generally poorer health of heavier smoking deprived mothers during pregnancy and thereafter and partly to the deprived smaller infant's adverse environment, which may include cold, poor diet, over crowding (inducing cross infection), lack of hygiene, and parental inadequacy or neglect. Sick, small babies in poor social circumstances are returned to hospital more promptly by general practitioners even for fairly minor degrees of illness.

It is interesting that, in contrast with those under 5 , deprived children aged 5-15 had $20 \%$ fewer general practitioner consultations than their controls and that their number of admissions to hospital was not significantly higher. One possible reason is that recurrent illness in infancy may confer a measure of immunity and hardiness later in childhood. A more likely explanation is that deprived children do not receive medical attention as often as they might, evidenced by their much higher non-attendances for medical appointments; thus some morbidity goes unrecorded. The higher morbidity associated with deprivation returns later in life. ${ }^{2}$

Mental disturbance among deprived children is hardly surprising, for parents unhappy amid the pressures of crowded deprivation will spin off behavioural problems onto their children. Contributory factors may be family 'rows' and instability, excessive noise and stress, poor recreational facilities, and inability to get away on holiday. Nonaccidental injuries tend to be commoner in lower social classes. ${ }^{5}$ A Newcastle study found that lower social class among children was associated with lower intelligence quotient, more borderline and educational subnormality, and more behavioural problems. ${ }^{6}$

The poor environment of deprived children undoubtedly contributes to their high casualty rate. Perusal of hospital casualty slips suggests that many of their home accidents result from hazards unforeseen or unheeded by parents, together with difficulty in supervising large families, while lack of suitable space to play inside and outside the home results in hazardous street activities.

Rates of immunisation showed the biggest disparity between deprived and endowed children. We attribute the poor state of the deprived group almost entirely to default rather than to ailments when 
immunisations were due. This results partly from the apathy of parents in the deprived group and partly from distrust: the anti-immunisation lobby with its banner headlines has had greatest impact on uninformed parents of low education and intelligence. The effect of the anti-pertussis campaign is evident in both groups of older children but is clearly diminishing in those under 5. More deprived children and controls are receiving immunisations and at earlier median ages, and the deprived children seem to be catching up somewhat on the controls, although they are still well behind.

Morbidity associated with deprivation will continue while that deprivation exists. The general practitioner can do little except attempt to cure the morbidity, help his deprived patients by counselling (particularly with regard to contraception and family limitation), and try to ensure that they receive the maximum of preventive care. For children that means immunisation and for their mothers preconception counselling ${ }^{7}$ and intensive antenatal care. ${ }^{8}$ As the deprived children under 5 visit the doctor more often than their controls opportunities for immunisation manifestly exist; clearly, we have not been making the most of them. To improve uptake of immunisation we have adopted the following measures for an open ended trial:

(1) For each deprived patient, whether child or adult, the front of the A4 medical record now shows the outstanding immunisations for all children in that household. Thus immunisation can be discussed and proffered for every child no matter who consults.

(2) When a child presents for any reason the doctor will, if appropriate, offer any outstanding immunisation. This is implemented immediately if possible as the structured system of making return appointments is largely ineffective.
(3) We have written to each household listing the outstanding immunisations of each child. Progress is monitored and reminders sent regularly to those who do not respond.

(4) Our health visitors have household lists of outstanding immunisations, which they discuss and encourage when visiting.

Our deprived community, although uncomplicated by sizable ethnic or religious minorities, is probably typical of many in Britain in the 1980s. Unfortunately, these deprived people are not obtaining the full benefits of the free at the time health care ordained by the welfare state to help counter social inequality.

We thank the Health Education Council for financial support and Dr I T Russell, Health Care Research Unit, University of Newcastle upon Tyne, for statistical advice.

\section{References}

1 Report of a Research Working Group. Inequalities in health. (The Black report.) London: HMSO, 1980.

2 Marsh GN, Channing DM. Deprivation and health in one general practice. $\mathrm{Br}$ Med $J$ 1986;292:1173-6.

${ }^{3}$ Marsh GN, Thornham JR. Changing to A4 folders and updating records in a "busy" general practice. Br Med J 1980;281:215-7.

${ }^{4}$ Central Statistical Office. Social trends. London: HMSO, 1984.

${ }^{5}$ Hart C, ed. Child care in general practice. London: Churchill Livingstone, 1977

6 Neligan G, Prudham D, Steiner H. The formative years. Oxford: Oxford University Press, 1974.

${ }^{7}$ Marsh GN. Modern obstetrics in general practice. Oxford: Oxford University Press, 1985.

" Marsh GN. New programme of antenatal care in general practice. $\mathrm{Br}$ Med $J$ 1985;291:646-8.

Correspondence to $\operatorname{Dr} \mathrm{G} \mathrm{N}$ Marsh, Norton Medical Centre, Harland House, Norton, Stockton-on-Tees TS20 1AH, England.

Received 7 November 1986 